\title{
Studying the Relationship of Identity-Genuineness and Desired Organizational Image on Insurance Companies Performance (Case Study: Iran Insurance)
}

\author{
Mehdi Shojaei Shad ${ }^{1}$, Kewmars Fallahi \\ Received:20.08.2015 \\ Revised:25.09.2015 \\ Accepted: 30.09.2015
}

\begin{abstract}
The purpose of current research is to study the relationship of identity, genuineness and organizational image with the performance of Iran Insurance Company that the methodology is descriptive-analytic, in terms of purpose, it is applicable and in terms of the method kind, it is a survey method. The statistical population of this research includes all employees of Iran Insurance in Tehran city. In order to analyze the obtained data, collected questionnaires, descriptive and inferential statatistical methods will be used. Therefore, in oorder to describe the responses given to the questionnaire questions of the research, the frequency distribution tables and the responses percent related to each one of the questions will be used and in order to test the hypotheses in inferential level, Spearman correlation test will be used, also in order to analyze the data, SPSS software will be applied. The results showed that there is meaningful relationship between the identity-genuineness -organizational image and performance of Iran Insurance Company.
\end{abstract}

Key words: export incentives, export volume, furniture

\section{Introduction}

Organizational identity is one of the concepts which have been considered in recent years. Each individual image of himself isn't formed only according to the internal factors, rather others and external social entities are involved in the formation of individual image of his identity. Each individual identity can not be formed in his behavior, rather it is determined in others' reaction. The identity isn't given to the individual; rather it is formed in interaction with directions constantly. A part of this interaction is with the organizations and individuals define their identities according to the membership in an organization or job; namely they introduce themselves with the organization in which worked or will work and the psychological ownership is happened in them.

An important issue in today organizations is the profileration of identity or multiple identities; namely the individuals because of working in different parts of the organization take multiplied identities to themselves. The organization managers should try that these identities to have synergy instead of contrariety. The identity synergy prevents from becoming sectional and

\footnotetext{
Author's Address

${ }^{1}$ Department of Business Administration, North Tehran Branch, Islamic Azad University, Tehran, Iran.

${ }^{2}$ Institute for Educational Research Academy of Scientific in Education and Commercial Management Department, Management and Social sciences Faculty, Tehran North Branch Islamic Azad University, Tehran, Iran Email: kewmarsf@gmail.com
}

sectional optimization.In addition to the intraorganizational multiple identities, another kind of multiple identities can be proposed in interorganizational level. Namely when individual is the member of different organizations, takes multiple identities to himself. For example, he is studying in Tehran University, works in Iran Khodro and he is a member of the nongovernmental organization of women heads of family. We should take care that the organizational identities made in these organizations are in conflict with each other; because having common organizational identity between the members is valuable for the organization.

Nowadays, the management experts and scientifics all are aware of this issue that obtaining the competitive advantage is the only index which shows that some organizations are superior over the other ones. Superior organizations through the ability to present the products and services with better conditions than their competitors guarantee more stability and longevity of their lives in today's changeable and complicated conditions. Obtaining the competitive advantage and becoming different organizations are dependent on having developed human sources which know a lot and create knowledge. Therfore, in order to train the knowledged and educated employees, a knowledged management system is much needed in the organizations that through it, the 
mentioned purposes can be achieved (Abbasi, 2008).

Responding to the following question is the main purpose of the writer:

What relation is there between the identitygenuineness-desired organizational image and insurance companies performance (case study: Iran Insurance)?
Evaluation of performance in each organization depends on numerous factors. The importance of evaluating 7 performances is no secret to anyone. Therefore identifying the factors which can be effective on the organizations performance seems a necessary affair. Meantime, with regard to the novelty of the issue in the spatial domain of the research (Iran Insurance), we can interprete that this research has high importance.

\section{Conceptual model of the research}

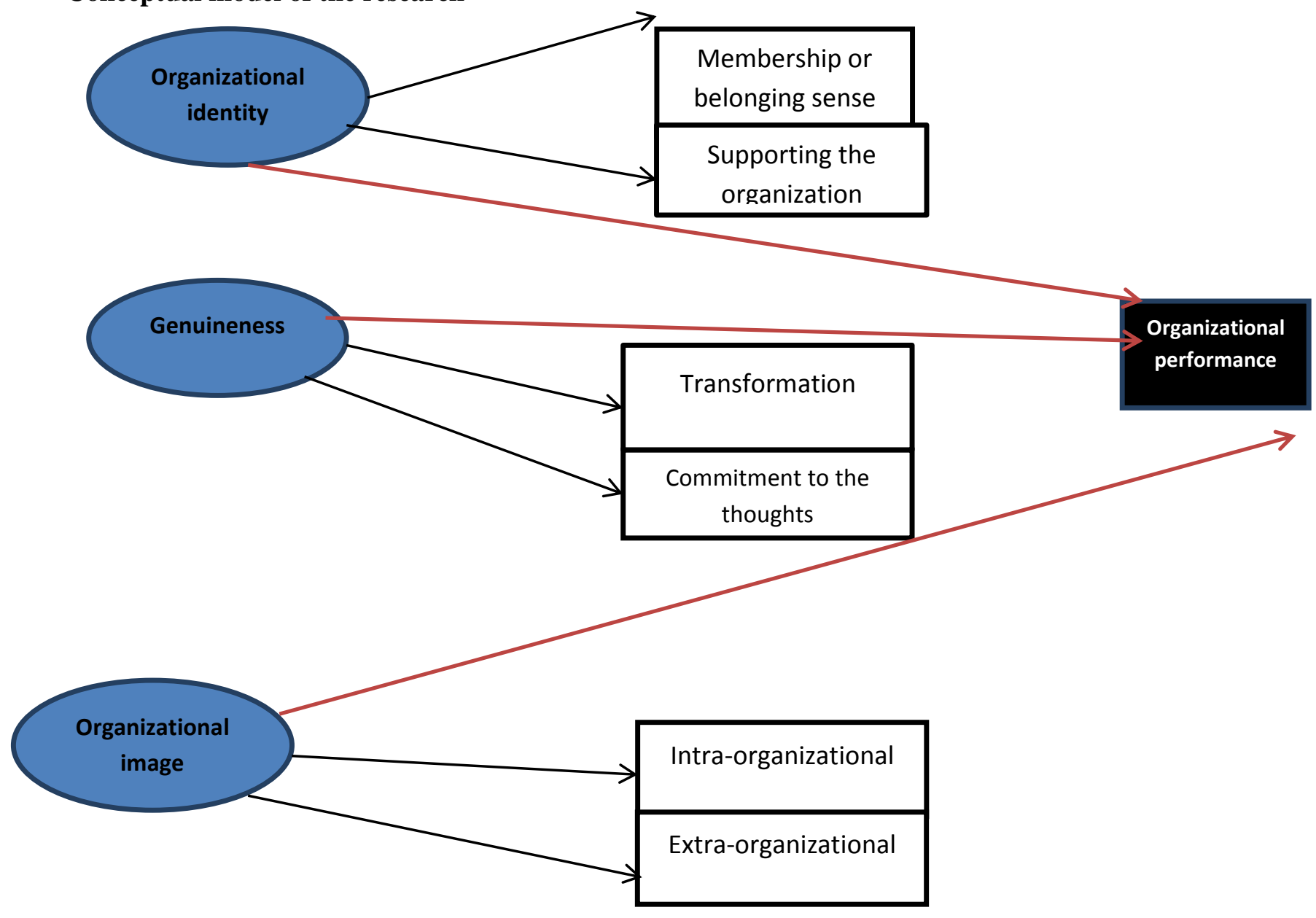

The conceptual model source: (Mirzamohammadi, 2014)

\section{Theoretical principles}

\section{Performance evaluation}

In order to understand the concept of performance evaluation, we should perceive the performance concept. Performance refers to the degree of doing the duties which complete an employee's job (Byars and Rue, 2008: page 216). And it shows that how an employee do the necessities of a job. Performance is often equated with effort which refers to consume the energy, but the performance is evaluated according to the activities results. For example, a student may apply great effort to be prepared for a test but he may receive low score. In this case, he has made great effort, but the performance has been low. According to Byars and Rue belief (2008: page 217), individuals' performance in a situation can be considered as the great result of mutual relation between: A) effort, B) abilities and C) role perceptions. "Effort" which is originated from arousal, refers to the amount of energy (physical or mental) that an individual uses in 
doing the duty. "Abilities" are the individual characteristics used in a job and "role perceptions" refer to the routes that individual believe should conduct their efforts aligned with doing their jobs. Noe and et al (2008, page 345) know the performance arising from personal characteritics, skills and like them.

\section{Strategy}

It is not bad at first the lexical root of strategy to be mentioned. Strategy word has been taken from Greek root of Strategema means compound army commander, Stratos means army and ago means leader. At first the strategy concept was applied with the meaning of technique, conducting, matching and coordinating the forces in order to achieve the war purposes in military sciences. In another place, strategy is a colletion of the main purposes and policies and general plans in order to achieve these purposes, it is defined in a manner that can explain these issues that we operate or will operate in what business or what kind organization.

\section{The organization culture}

The purpose of organizational culture is a system of common inference that the members have in relation with an organization and the same property causes to separate two organizations from each other, Chris Arjeris calls the organizational culture as an alive system and defines it in a form of behavior that people reveal from themselves in practice, a way that they really think and feel according to it and a method which they really behave with each other (Irannejad Parizi, 2000).

\section{Organizational structure}

Organization in different periods of its life has traversed different stages such as outburst, change and development. In this transition, change in organizational structure has been in the center of change and development of organization (Ichi Oumi, 1992). The writers have classified the changes which have been created in the organizational structure with different methods and each one of them has studied the effect of content factors like environment, strategy, technology and... on the organization structure and according to this, they have introduced different structures (Robinz, 1987).

\section{Organizational abilities and talents}

The organizations often do marketing for their sale; the organization marketing includes the activities which are done for creating, keeping or changing the thought manner or addressees' behavior to an organization. Creative marketing force, new methods of marketing and having sufficient financial sources for marketing are accounted as organization abilities. On the other hand, having updated and advanced technologies which help to the organization in creating the value are accounted as the special abilities of the organization (Amitabh 1, 2012).

\section{The research background}

1) John S. Walton \& Gisele Guarisco (2015) in a research entitled «organizational structural issues according to the components of commitment and organizational image in international exchanges of educational institutions " showed whatever the employees' image is higher than the organization and its purposes and its transparacy is more desired, the organizational commitment will be increased and due to this, the performance is also transformed.

2) Mc Crthy, A.F (2010): whenever the organization has a positive image, the addressees, beneficiaries and social partners or its customers generally consider the behaviors and decisions of that organization and also their experiences with it positively and will accompany with them more. While if these individuals or groups have a negative image of the organization, the performance, behavior and decisions of that organization are also influenced by negative considerations and interpretations.

3) Isaee Mohammadtaghi, Afzali Hamidreza, Zia Mohammad (2013): leaders by using of spirituality indexes in the organization or group, prepare both a kind of internal incentive for themselves and the fields for external incentive of their followers. Spiritual leaders that the value of affairs is important for them, the followers activities in the organization are meant by connecting them to their deep internal values, with regard to this issue that the organizational identification has a main effect on the behavior of the organization members and consequently performance and achieving the purposes.

\section{Material \& Method}

The purpose of current research is to study the relationship of genuineness, identity and organizational picture with performance of Iran Insurance Company that the methodology is descriptive-analytic and in terms of purposes it is applicable and in terms of the method kind, it is a survey research. The statistical population of this research includes all employees of Iran Insurance in Tehran city. Also the statistical samples of this 
research have been selected completely randomly and they are 190 individuals. In order to evaluate the performance of this organization, the performance evaluation questionnaire of Khalili (2013) will be used which has 45 five-option questions and it is according to the Likret spectrum. The Cronbach's alpha coefficient of this questionnaire has been 84 percent.

In order to analyze the obtained data, collected questionnaire and statistical descriptive and inferential methods will be used. In this order that for describing the responses given to the questionnaire questions of the research, frequency distribution tables and the responses percent related to each one of the questions will be used and in inferential level in order to test the hypotheses, Pearson correlation test will be used and also in ordrr to analyze the data, SPSS software will be applied.

The statistical tests applied in this research are stated as follows:

1. Smirnov test (in order to identify the normality of variables)

2. T-TEST (in order to identify the normality of data)

3. Pearson correlation coefficient (in order to identify the relationship between the variables)

4. F-test or the same Fridman (in order to grade the effective variables in the research)

\section{The research hypotheses}

data

\section{The main hypothesis}

There is meaningful relationship between the identity-genuineness-organizational picture and the performance of Iran Insurance Company.

\section{Subsidiary hypotheses}

1) There is meaningful relationship between the identity and performance of Iran insurance Company.

2) There is meaningful relationship between the identity and Iran Insurance Company.

3) There is meaningful relationship between the organizational image and performance of Iran Insurance Company.

\section{The research purposes}

The main purpose:

Studying the relationship of genuineness, identity and organizational image with performance of Iran Insurance Company

\section{Subsidiary purposes:}

1) Studying the relationship of identity with performance of Iran Insurance Company

2) Studying the relationship of genuineness with performance of Iran Insurance Company

3) Studying the relationship of organizational image with performance of Iran Insurance Company

Data analysis

Descriptive analysis of research

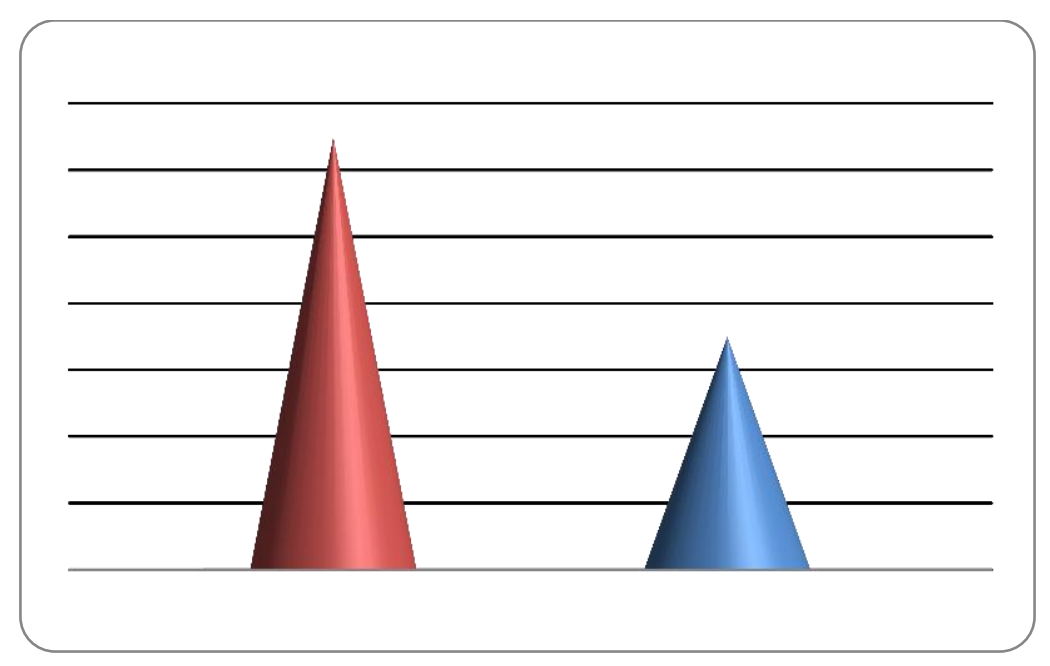

Fig. 1-Gender distribution

The diagram shows that 65 percent of responders are men and the rest includes the women. 


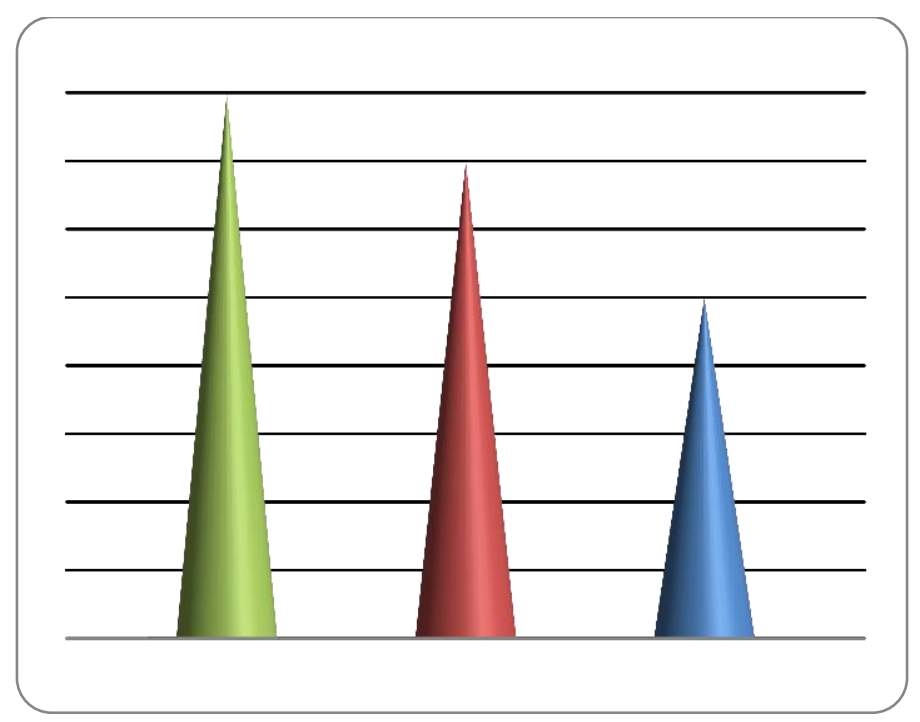

\section{Fig 2-Age group distribution}

The above diagram shows that the most frequency is related to the age group more than 45 years with 40 percent of responders and the least of it is related to the age group less than 35 years which have allocated 25 percent to themselves.

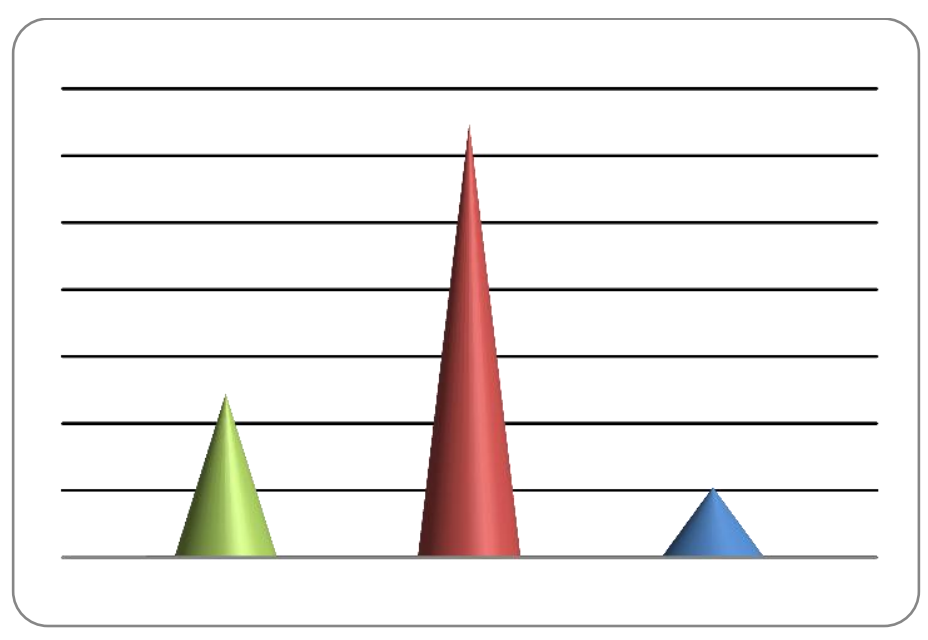

\section{Fig 3-academic degree distribution}

The above diagram shows that the most frequency is related to the BA academic degree with 65 percent of responders and the least of it is related to the academeic degrees higher than BA which have allocated 24.5 percent to themselves.

\section{6-2.Studying the research hypotheses 6-2-1. Testing the normality of variables}

Since the normality of variables is the necessary condition for doing the related tests, at first we do the normality test for the variables.
The null hypothesis and the alternative hypothesis of the normality test are as follows:

The varibales distribution of $\mathrm{H} 0$ : entity is normal The variables distribution of $\mathrm{H} 1$ : entity isn't normal

In order to test the above hypotheses, Kolmogorov-Smirnov test is used. In this test whenever the meaningfulness level is less than $5 \%$, the null hypothesis in the confidence level of $95 \%$ is rejected 
Table 1- Kolmogorov-Smirnov test of the variables

\begin{tabular}{|l|l|l|l|}
\hline Variable & $\begin{array}{l}\text { First } \\
\text { hypothesis }\end{array}$ & $\begin{array}{l}\text { Second } \\
\text { hypothesis }\end{array}$ & $\begin{array}{l}\text { Third } \\
\text { hypothesis }\end{array}$ \\
\hline Number & 384 & 384 & 384 \\
\hline Mean & $612 / 3$ & $298 / 3$ & $580 / 3$ \\
\hline Standard deviation & $61 / 0$ & $65 / 0$ & $55 / 0$ \\
\hline $\begin{array}{l}\text { The absolute value of the } \\
\text { highest standard deviation }\end{array}$ & $092 / 0$ & $139 / 0$ & $085 / 0$ \\
\hline $\begin{array}{l}\text { The highest positive standard } \\
\text { deviation }\end{array}$ & $083 / 0$ & $096 / 0$ & $085 / 0$ \\
\hline $\begin{array}{l}\text { The highest negative standard } \\
\text { deviation }\end{array}$ & $092 / 0-$ & $139 / 0-$ & $085 / 0-$ \\
\hline Kolmogorov-Smirnov & $126 / 1$ & $131 / 0$ & $117 / 1$ \\
\hline sig & $078 / 0$ & $659 / 0$ & $084 / 0$ \\
\hline
\end{tabular}

With regard to the output of the above table, the value- $\mathrm{P}$ is higher than 0.05 , (value- $\mathrm{P}>0.05$ ). Therefore H0 hypothesis will not be rejected and H1 hypothesis which indicates the abnormality of the variables will be rejected.

\section{6-2-2- Inferential statistic}

First hypothesis:

$$
\begin{cases}H_{0}: & \mu \leq 3 \\ H_{1}: & \mu>3\end{cases}
$$

Statistical hypothesis:

\begin{tabular}{|l|l|l|l|l|l|l|}
\hline Hypothesis & Number & Mean & $\begin{array}{l}\text { Standard } \\
\text { deviation }\end{array}$ & $\begin{array}{l}\text { Calculated - } \\
\text { T }\end{array}$ & Pv & Test result \\
\hline First & 190 & $\mathbf{3 . 6 1 2 0}$ & $\mathbf{0 . 6 0 7 9 8}$ & $\mathbf{1 9 . 7 2 5}$ & $\mathbf{0 . 0 0 0}$ & $\begin{array}{l}\text { H0 } \\
\text { rejected is }\end{array}$ \\
\hline
\end{tabular}

With regard to the information of the above table, because Pv-calculated is less than 0.05, we conclude that the null hypothesis is rejected.

Another study accomplished in this research is to grade the factors of each question which has been done by using of Fridman test.

H0: the effect of the factors proposed in the first hypothesis from the perspective of responders is the same.

H1: the effect of the factors proposed in the first hypothesis from the perspective of responders isn't the same.

\begin{tabular}{|l|l|l|}
\hline Questions & $\begin{array}{l}\text { The mean of } \\
\text { grades }\end{array}$ & Grade \\
\hline 1 & 3.47 & Fourth \\
\hline 2 & 3.76 & Second \\
\hline 3 & 3.87 & First \\
\hline 4 & 3.26 & Fifth \\
\hline 5 & 2.98 & Sixth \\
\hline 6 & 3.66 & Third \\
\hline Statistic & \multicolumn{2}{|l|}{$\chi^{2}=73.810, d f=5, P_{v}=0.000$} \\
\hline
\end{tabular}

Second hypothesis: statistical hypothesis:

$\begin{cases}H_{0}: & \mu \leq 3 \\ H_{1}: & \mu>3\end{cases}$

\begin{tabular}{|l|l|l|l|l|l|l|}
\hline Hypothesis & Number & Mean & $\begin{array}{l}\text { Standard } \\
\text { deviation }\end{array}$ & T-calculated & Pv & Test result \\
\hline Second & 190 & 3.2977 & .65429 & 8.917 & .000 & $\begin{array}{c}\text { HO } \\
\text { rejected. }\end{array}$ \\
\hline
\end{tabular}


With regard to the information of above table, because $\mathrm{Pv}$-calculated is less than 0.05, we conclude that the null hypothesis is rejected.

Another study accomplished in this research is to grade the factors of each question which has been done by using of Fridman test.

H0: the effect of the factors proposed in the second hypothesis from the perspective of responders is the same.

H1: the effect of the factors proposed in the second hypothesis from the perspective of responders isn't the same.

\begin{tabular}{|l|l|l|}
\hline Questions & $\begin{array}{l}\text { The mean of } \\
\text { grades }\end{array}$ & Grade \\
\hline 1 & 3.38 & Fourth \\
\hline
\end{tabular}

\begin{tabular}{|l|l|l|}
\hline 2 & 3.12 & Fifth \\
\hline 3 & 3.78 & Second \\
\hline 4 & 3.66 & Third \\
\hline 5 & 3.01 & Sixth \\
\hline 6 & 4.05 & First \\
\hline Statistic & \multicolumn{2}{|l|}{$\chi^{2}=107.184, d f=5, P_{v}=0.000$} \\
\hline
\end{tabular}

Third hypothesis: statistical hypothesis:

$$
\begin{cases}H_{0}: & \mu \leq 3 \\ H_{1}: & \mu>3\end{cases}
$$

\begin{tabular}{|l|l|l|l|l|l|l|}
\hline Hypothesis & Number & Mean & $\begin{array}{l}\text { Standard } \\
\text { deviation }\end{array}$ & T-calculated & $\mathrm{Pv}$ & Test result \\
\hline Second & 190 & 3.5802 & .54579 & 20.832 & .000 & $\begin{array}{c}\text { HO is } \\
\text { rejected. }\end{array}$ \\
\hline
\end{tabular}

With regard to the information of above table, because Pv-calculated is less than 0.05, we conclude that the null hypothesis is rejected. Another study accomplished in this research is to grade the factors of each question which has been done by using of Fridman test.
H0: the effect of the factors proposed in the third hypothesis from the perspective of responders is the same.

H1: the effect of the factors proposed in the third hypothesis from the perspective of responders isn't the same.

\begin{tabular}{|l|l|l|}
\hline Questions & The mean of grades & Grade \\
\hline 1 & 2.93 & Third \\
\hline 2 & 2.99 & Second \\
\hline 3 & 3.61 & First \\
\hline 4 & 2.92 & Fourth \\
\hline 5 & 2.55 & Fifth \\
\hline Statistic & \multicolumn{2}{|l|}{$\chi^{2}=106.021, d f=4, P_{v}=0.000$} \\
\hline
\end{tabular}

\section{Conclusion and suggestions}

The hypotheses results

First hypothesis: with regard to the $\mathrm{Pv}$ calculated, the null hypothesis is rejected and the research hypothesis is accepted. Namely there is meaningful difference between the factors proposed in the first hypothesis. And the means show that the third and fifth factors have allocated in order the highest and lowest effects to themselves. The result obtained from this hypothesis conforms to the research result of Shami, 2002.
Second hypothesis: with regard to the $\mathrm{Pv}$ calculated, the null hypothesis is rejected and the research hypothesis is accepted. Namely there is meaningful difference between the factors proposed in the second hypothesis. And the means show that the sixth and fifth factors have allocxated in order the highest and lowest effects to themselves. The findings result in the field of second hypothesis conforms to the research result of Dehghan 2007.

Third hypothesis: with regard to the $\mathrm{Pv}$ calculated, the null hypothesis is rejected and the research hypothesis is accepted. Namely there is 
meaningful difference between the factors proposed in the third hypothesis. And the means show that the third and fifth factors have allocated in order the highest and lowest effects to themselves. The result obtained from this hypothesis conforms to the research result of Shami, 2002.

\section{Suggestions}

1. Studying and explaining the concept, conditions and dimensions, necessities and benefits of organizational performance

2. Increasing the individuals' commitment and ability and effective information in the organizational structure field

3. Increasing the learning skill in the organizational components field

4. Creating the organizational culture in the field of management on establishment of strategic thoughts in the organization.

5. Providing the necessary facilities in order to improve the performance

6. Designing the processes and procedures for group learning

\section{References}

Asadi, Hassan; Ghorbani, Mohammadhossein, 2008. The relationship between commission and organizational integration in the experts of physical education organization of Iran Islamic Republic, Olympic, pages 59-69: (44).

Amini, Bibi Akram, 2007. Citizenship-organizational behavior: concepts, background, benefits and models, journal of organizational knowledge management, No.24.

Toureh, Naser. 2006. Recognizing the factors of citizenship-organizational behavior and studying its relationship with organizational performance, management culture, fourth year, No.12, pages 31 63.

Hassani Kakhaki, Ahmad, 2006. Studying the effect of citizenship-organizational behaviors on the customer perception of the services quality, customer satisfaction and behavorial intentions, Master thesis, management college, Tehran University.

Robinz, Stephen pie 2008. Translators: Parsaeian, Ali. Arabi, seyed Mohammad. Principles of organizational behavior, Tehran: culture researches office. $20^{\text {th }}$ edition, pages $112-363$.

Rahimi, Eskandar, 2009. Studying the factors of occupational tension and its relationship with job satisfaction in employees of physical education in Fars province. Olympic, pages 7-17: (45).

Abbaspour, Asghar. 2006. "Studying the relationship between the human sources measures and citizenship-organizational behaviors in Mellat Bank employees". Master thesis, management college, Tehran University.

Moghimi, Mohammad 2005. Citizenshiporganizational behavior from theory to practice, management culture, No.11, page 38 .

Nouri, Ali, 2008. Studying the effect of mediator role of citizenship-organizational behavior on the services quality: case study: five-star hotel of Pars, Master thesis, college of administrative knowledges and economy, Ferdousi University.

Adcock, B. P. 1999. The role of organizational citizenship behavior in the linkage of employee and customer satisfaction. University of South Florida.

Allen, D. G., Shore, L. M., \& Griffeth, R. W. 2003.The role of perceived organizational support and supportive human resource practices in the turnover process. Journal of Management, 29, 99118.

Alston,O., 2005.The effect of web portal characteristics, expectancies, and negative word of mouth on perceived institutional support and organizational citizenship behavior. $\mathrm{PhD}$ thesis. University of Pittsburgh.

Anika, T. 2008. The effect of organizational, supervisor and coworker support on perceived job stress and attitudinal outcomes. Master thesis,California state university.

Aoyagi, W. M., Cox, H. R., McGuire, T. R. 2008. Organizational citizenship behavior in sport: Relationship with leadership, team cohesion, and athletic satisfaction. Journal of Applied Sport Psychology, 20, 25-41.

Appeibam, S., bartolomucci, N., beaumier, E., Boulanger, j., Corrigan, R., dore, I. 2004. organizational citizenship behavior: a case study of culture, leadership and trust. management decision, 42, 13-40.

Appenzeller, H. 1993..Managing sports and risk management strategies. Durham, NC; Carolina Academic Press.

Armeli, S. Eisenberger, R., Fasolo, P., \& Lynch, P. 1998. Perceived organizational support and police performance: The moderating influene of socioemotional needs. Journal of Applied Psychology, 83, 288-297. 